University of St. Thomas, Minnesota

UST Research Online

Operations and Supply Chain Management

Faculty Publications

Operations and Supply Chain Management

2013

New Product Development: Impact of Project Characteristics and Development Practices on Performance

\author{
Sohel R. Ahmad \\ St. Cloud State University, ahmad@stcloudstate.edu \\ Debasish N. Mallick \\ University of St.Thomas, Minnesota, dnmallick@stthomas.edu \\ Roger G. Schroeder \\ University of Minnesota - Twin Cities, rschroed@umn.edu
}

Follow this and additional works at: https://ir.stthomas.edu/ocbopmtpub

Part of the Business Administration, Management, and Operations Commons, Management Sciences and Quantitative Methods Commons, and the Operations and Supply Chain Management Commons

This Article is brought to you for free and open access by the Operations and Supply Chain Management at UST Research Online. It has been accepted for inclusion in Operations and Supply Chain Management Faculty Publications by an authorized administrator of UST Research Online. For more information, please contact asle4660@stthomas.edu. 


\title{
New Product Development: Impact of Project Characteristics and Development Practices on Performance*
}

\author{
Sohel Ahmad, Debasish N. Mallick, and Roger G. Schroeder
}

Concurrent product development process and integrated product development teams have emerged as the two dominant new product development (NPD) "best practices" in the literature. Yet empirical evidence of their impact on product development success remains inconclusive. This paper draws upon organizational information processing theory (OIPT) to explore how these two dominant NPD best practices and two key aspects of NPD project characteristics (i.e., project uncertainty and project complexity) directly and jointly affect the NPD performance. Contrary to the "best practice" literature, the analysis, based on 266 NPD projects from three industries (i.e., automotive, electronics, and machinery) across nine countries (i.e., Austria, Finland, Germany, Italy, Japan, Korea, Spain, Sweden, and the United States), found no evidence of any direct impact of process concurrency or team integration on overall NPD performance. Instead, there is evidence of negative impact of the interaction between project uncertainty and concurrent NPD process and positive impact of the interaction between project complexity and team integration on overall NPD performance. Moreover, the study found no evidence of any direct negative impact of project uncertainty or complexity on overall NPD performance as suggested in the literature, but found evidence of a direct positive relationship between project complexity and overall NPD performance.

The practical implications of these results are significant. First, neither process concurrency nor team integration should be embraced universally as best practice. Second, process concurrency should be avoided in projects with high uncertainty (i.e., when working with unfamiliar product, market, or technology). Finally, team integration should be encouraged for complex product development projects. For a simple product a loosely integrated team or a more centralized decision process may work well. However, as project complexity increases, team integration becomes essential for improved product development. There is no one-size-fits-all solution for managing NPD projects. The choice of a product development practice should be determined by the project characteristics.

\section{Introduction}

$\mathrm{D}$ uring the past two decades, concurrent product development process and integrated (crossfunctional) product development teams have emerged as the two dominant best practices for new product development (NPD; Barczak, Griffin, and Kahn, 2009; Gerwin and Barrowman, 2002). These two best practices have attracted significant attention from industry, as well as from the academic literature (Clark and Fujimoto, 1991; Griffin, 1997b; Hauptman and Hirji, 1996; Zirger and Hartley, 1996) and practitioner literature (Clausing, 1994; Imai, Nonaka, and Takeuchi, 1985). However, the performance impact of these best practices

Address correspondence to: Debasish N. Mallick, Department of Operations \& Supply Chain Management, Opus College of Business, University of St. Thomas, 1000 La Salle Avenue \#SCH 435, Minneapolis, MN 55403. E-mail: dnmallick@stthomas.edu. Tel: 651-962-4144.

* This research project was partially funded by research grants from St. Cloud State University and the University of St. Thomas. remains inconclusive (Barczak et al., 2009; McDonough, 2000).

The concurrent product development process involves partial or completely parallel execution of certain activities in the NPD process (Clausing, 1994), and an integrated (cross-functional) product development team consists of participants from all the major functions in a product development project (Blackburn, 1991; Rosenthal, 1992). Proponents of these practices argue that parallel execution of product development tasks and/or tighter team integration leads to improved NPD performance. These arguments are often based on the assumption that concurrent processes and integrated teams will arrive at a better design in a shorter time and, as a consequence, will lead to improved market share and profitability (Blackburn, 1991; Clausing, 1994; Rosenthal, 1992). However, several scholars have pointed out that development speed is only one of the several determinants of NPD success and these best practices could actually have a negative impact on the overall NPD performance (Crawford, 1992; Meyer and Utterback, 
1995; Olson, Walker, and Ruekert, 1995). In fact, the latest PDMA Best Practice Survey (2004) indicates that although cross-functional development processes are being adopted widely (69\% of the respondents), NPD success rate has not improved but remained stable between 58\% and 59\% during the past two decades (Barczak et al., 2009).

Literature on the concurrent product development process (hereafter also referred to as process concurrency) and team integration originated in the practitioner literature and primarily consists of single company case studies that cannot be generalized (Griffin, 1997b; Parry, Song, De Weerd-Nederhof, and Visscher, 2009). The few empirical studies that have attempted to generalize these findings focus solely on their impact on development speed (Gerwin and Barrowman, 2002). Although development speed is a key determinant of NPD success, it is

\section{BIOGRAPHICAL SKETCHES}

Dr. Sohel Ahmad is a professor of operations management in G. R. Herberger College of Business at St. Cloud State University. $\mathrm{He}$ received his $\mathrm{PhD}$ in operations management from the University of Minnesota. His research interests include lean systems, HRM-OM interface, and knowledge and innovation management. Professor Ahmad has published in scholarly journals including Journal of Operations Management, Production \& Operations Management, and International Journal of Operations \& Production Management.

Dr. Debasish N. Mallick is an associate professor of technology and operations management in Opus College of Business at the University of St. Thomas. Previously, he worked in industry and taught at Virginia Commonwealth University, Boston College, and the University of Minnesota. He also directed the new product design and business development program at the University of Minnesota. He received his B.Tech. (Honors) in mechanical engineering from the Indian Institute of Technology, his MBA from the University of Arkansas, and his $\mathrm{PhD}$ in management from the University of Texas at Austin. His research interests are in new product development and technology management. His work has appeared in several academic journals including Journal of Operations Management, Production and Operations Management, Journal of Engineering and Technology Management, Design Management Journal, European Journal of Operational Research, European Journal of Innovation Management, and JPIM.

Dr. Roger G. Schroeder is the Donaldson Chair in Operations Management Emeritus at the Carlson School of Management, University of Minnesota. He is also Professor of Operations Management at Tilburg University, the Netherlands. He received his $\mathrm{PhD}$ from Northwestern University and has publications in major academic journals including Management Science, Journal of Operations Management, Academy of Management Journal, and Production and Operations Management. He is a fellow of the Decision Sciences Institute and of the Production and Operations Management Society. He received the Lifetime Scholarship Achievement Award from the Academy of Management, Operations Management Division, and a Career Research Award from the Carlson School of Management. He has also been inducted into the University of Minnesota Academy of Distinguished Teachers. only one of the several determinants of NPD success such as product performance, market share, profitability, and cost (Ledwith and O'Dwyer, 2009; Mallick and Schroeder, 2005). Moreover, empirical evidence of the relationship between development speed and the other NPD success measures such as market share and profitability has been contradictory (Langerak, Hultink, and Griffin, 2008). As a result the net impact of these two best practices on the overall NPD performance remains an open question.

Scholars have suggested that product development practices should be dependent on the project characteristics (Fitzsimmons, Kouvelis, and Mallick, 1991; Gerwin and Susman, 1996; Griffin, 1997b; Krishnan and Ulrich, 2001; Langerak et al., 2008; Olson et al., 1995; Olson, Walker, Ruekert, and Bonnerd, 2001; Zirger and Hartley, 1996). Also, as best practices become mature it is important to find out when and why these practices work (Sousa and Voss, 2008). Following their suggestion, we draw upon organizational information processing theory (OIPT; Galbraith, 1974; Kitchen and SpickettJones, 2003), a variant of the contingency theory (CT; Lawrence and Lorsch, 1967; Thompson, 1967; Woodward, 1958), to examine how these two dominant NPD practices, i.e., the concurrent product development process and integrated product development teams, and two aspects of NPD project characteristics, i.e., product complexity and uncertainty, directly and jointly relate to overall NPD performance. Six hypotheses are tested using a cross-sectional survey of 266 NPD projects from three industries (i.e., automotive, electronics, and machinery) across nine countries (i.e., Austria, Finland, Germany, Italy, Japan, Korea, Spain, Sweden, and the United States). Contrary to the "best practice" literature, the study found no evidence of any direct impact of process concurrency or team integration on overall NPD performance. Instead, there is evidence of negative impact of the interaction between project uncertainty and process concurrency and positive impact of the interaction between project complexity and team integration on overall NPD performance. Moreover, the study found no evidence of any direct negative impact of product uncertainty or complexity on NPD performance as suggested in the literature (De Brentani, 2001; Griffin, 2002; Olson et al., 1995; Sheremata, 2000) but found evidence of a direct positive impact of project complexity on NPD performance.

The study makes several contributions to the NPD literature and practice. First, this study presents a contingency framework based on OIPT to better understand their interaction with project characteristics and the 
impact on overall NPD performance. Next, this study empirically tests the direct effect and interaction effect of project characteristics and development practices on overall NPD performance. Unlike previous studies (Ettlie, 1995; Hauptman and Hirji, 1996; Zirger and Hartley, 1996) that only focused on a single dimension (e.g., product development speed), this study used a multidimensional performance measure, thus providing a better understanding of the performance effect of these practices. Finally, the past studies are mostly based on a small and often a convenience sample (Ettlie, 1995; Hauptman and Hirji, 1996; Olson et al., 1995, 2001; Zirger and Hartley, 1996). The use of a multi-industry, multicountry database extends existing literature with improved generalizability of the findings (Bstieler, 2005; Hauptman and Hirji, 1996; Luo, Mallick, and Schroeder, 2010; Mishra and Shah, 2009).

The managerial implications of these findings are significant. First, neither process concurrency nor team integration should be embraced universally as best practice. Second, process concurrency should be avoided in projects with high uncertainty (i.e., when working with unfamiliar product, market, and technology). Finally, team integration should be encouraged for complex product development projects. For a simple product a loosely integrated team or a more centralized decision process may work well. However, as project complexity increases, team integration becomes essential for improved product development. There is no one-size-fitsall solution for managing NPD projects. The choice of a product development practice should be determined by the project characteristics.

The rest of the paper is organized as follows. The second section presents a brief review of the literature on the performance implications of NPD process and NPD team. The theoretical foundation and the main argument of this study are presented as a set of testable hypotheses in the third section. The fourth section contains a discussion of the data collection, measurement, and research methods used to test the proposed hypotheses. Results are discussed in the fifth section. The summary of the contributions, limitations, and some suggestions for future research are presented in the sixth section.

\section{Review of Relevant Literature}

A significant body of literature has emerged on process concurrency and team integration during the past two decades. Gerwin and Barrowman (2002) provide an extensive review of this literature. We only provide a brief summary of the literature as it relates to the relationship between project characteristics (i.e., uncertainty and complexity) and these two best practices. For the purpose of this review we organize our exposition into three segments: (1) literature on project characteristics; (2) literature on the two best practices; and (3) literature on the interaction between project characteristics and these two best practices.

\section{Literature on Project Characteristics (Uncertainty and Complexity)}

In the literature uncertainty and complexity have been identified as the two key characteristics of an NPD project that affect performance (Clark and Fujimoto, 1991; Eisenhardt and Tabrizi, 1995; Fitzsimmons et al., 1991; McDonough, 1993; Tatikonda and Rosenthal, 2000a, 2000b). The literature has argued that uncertainty and complexity make NPD projects difficult and will have negative impact on NPD performance. However, empirical evidence supporting this argument remains inconclusive. Although a large number of empirical studies have examined the relationship between uncertainty and NPD performance, findings from these studies are often contradictory and incomparable because of the inconsistency of the measures they use. At the same time, the relationship between complexity and NPD performance has remained relatively underexplored (Griffin, 1997b; Jacobs, 2007).

A variety of terminologies has been used to define complexity and uncertainty such as task difficulty (McDonough, 1993), product and market newness (Booz Allen Hamilton, Inc., 1968), content and scope (Clark, 1989), high growth rates, technology change and competition (Eisenhardt and Tabrizi, 1995), and technology novelty (Larson and Gobeli, 1989; Tatikonda and Rosenthal, 2000a). Moreover, these studies use a wide range of performance measures as dependent variables, making it difficult to draw any reasonably consistent conclusion from these studies.

Clark (1989, p. 1247) defined project "scope" as "the extent to which a new product is based on unique parts developed in-house" to examine the effects of uncertainty on product development performance in a study of 29 product development projects in 20 firms in the automobile industry in the United States, Japan, and Europe. This study reported a negative impact of project "scope" on performance measured by lead time and cost. A subsequent study (Clark and Fujimoto, 1991) reported that the introduction of new pioneering components did not have any impact on engineering lead time, engineering 
hours, or product quality. They also failed to find any effect of complexity, as defined by project content (e.g., platform size, market size, and product variety), on performance. A study of the automotive industry found that incremental projects (with lower uncertainty) reduce development time but decrease product quality (Clark and Fujimoto, 1991).

A study of 546 NPD projects by Larson and Gobeli (1989) failed to find any relationship between uncertainty and technical performance, cost, schedule, and overall results. Uncertainty in this study was measured by technology novelty. Another study of 32 small product development projects also failed to find any relationship between the familiarity of technology and product development speed (McDonough and Barczak, 1992). However, further study using the same sample reported a negative impact of technical difficulty with product development speed (McDonough, 1993).

Meyer and Utterback (1995) studied a portfolio of 40 product development projects in a single firm. Their findings suggest that product technology newness has a positive association with development time, but they failed to find any association between process technology newness as suggested by Wheelwright and Clark (1992) and Clark and Fujimoto (1991). This study did not include effects of complexity and $R \& D$ resource.

A study of 120 product development projects failed to show any association between technology novelty or complexity and overall project failures (Tatikonda and Rosenthal, 2000b). However, a negative association between technology novelty and unit cost and time-tomarket, and a negative association between complexity and unit cost were reported. Complexity in these studies was measured by technology interdependence, objective novelty, and project difficulty. Uncertainty was measured by technology novelty.

Overall, there is a strong theoretical argument that project uncertainty and complexity has a negative impact on NPD performance, but empirical evidence supporting this assertion has been less clear. A meta-analysis of 17 published papers (Gerwin and Barrowman, 2002) did not find any association between an incremental approach (i.e., low uncertainty) and reduction in development time. However, when the sample was further divided into two groups based on the performance metric used (i.e., development time and development time goal), the metaanalysis of eight published papers produced evidence of correlation between an incremental approach and development time, but the nine studies did not produce any evidence of a correlation between an incremental approach and development goal.
The Literature on NPD Practices (Process Concurrency and Team Integration)

Process concurrency represents the degree to which different organizational functions simultaneously conduct project work. Process concurrency has also been identified as parallel development, concurrent engineering, and simultaneous engineering in the literature (Clausing, 1994). Several empirical studies have reported a positive association between process concurrency and development speed (Hauptman and Hirji, 1996; Zirger and Hartley, 1996). A meta-analysis of 11 published papers indicated the presence of a positive correlation between process concurrency and development time (Gerwin and Barrowman, 2002).

The relationship between team integration and NPD performance is relatively less clear. Team integration is also known as multi-functional team or cross-functional team integration in the literature. Cross-functional teams are self-managing project groups with representatives from a company's relevant departments (Blackburn, 1991; Rosenthal, 1992). Several studies report a positive effect of team integration on product development performance (McDonough, 2000). A survey of 112 product development professionals indicates that increased use of cross-functional teams is related to higher project success (McDonough, 2000). At the same time, several scholars have suggested that using cross-functional teams may in fact increase goal failure (Cooper and Kleinschmidt, 1994; Rusinko, 1999). Moreover, several scholars have reported that increasing team diversity, presumably beyond a certain point, has no effect on performance (Ancona and Caldwell, 1992; Moffat, 1998; Scott, 1997). In fact, a study of 233 manufacturing firms found a negative impact of cross-functional integration on development speed and no significant impact on profitability (Langerak and Hultink, 2005). Similarly, a survey of 123 engineering managers found a negative impact of design and manufacturing integration on project success (Rusinko, 1999). Also, a meta-analysis of nine published studies did not find any correlation between team integration and development time reduction. Although a subset of four out of nine studies indicated a possible correlation between the use of cross-functional teams and development time, the remaining five studies did not find any correlation between the use of cross-functional teams and development time or goal failure (Gerwin and Barrowman, 2002).

However, product development speed is only one of the several determinants of NPD performance (Mallick and Schroeder, 2005). The impact of these two practices 
on other critical dimensions of NPD performance such as cost, quality, market share, and profitability has either been negative or ignored. Moreover, empirical studies connecting product development speed and NPD performance remain inconclusive (Langerak et al., 2008). Also, these studies differ widely in their conceptualization and operationalization of process concurrency and team integration. Process concurrency and process formality have been used interchangeably. While a cross-functional team can be organized in many different ways, some studies have just indicated if a cross-functional team was used or not (Gerwin and Barrowman, 2002).

In a study of 44 projects, Zirger and Hartley (1996) found that projects with greater concurrency were developed faster. However, in a sample of 50 projects ranging from chemical to shipbuilding, it was found that "overlapping problem solving" was associated with meeting quality goals but not cost and time goals (Hauptman and Hirji, 1996). Similarly, Ettlie's (1995) study of firm-level practices at 43 companies found that a "functionallyintegrated product process regimen" is not associated with shorter development time. A meta-analysis of 11 published papers indicated the presence of a positive correlation between process concurrency and development time (Gerwin and Barrowman, 2002). A study of 29 completed software projects also indicated that a flexible product development process is better suited for projects with high uncertainty (MacCormack, Verganti, and Iansiti, 2001). Our review of the literature indicates that the majority of the studies have focused on the impact of process concurrency on project schedule-related measures such as development time and development time goal while ignoring other dimensions that affect NPD success. Therefore, the literature is inconclusive on the effect of process concurrency on the overall NPD performance.

\section{Literature on Effects of Project Characteristics on NPD Practices}

Several scholars have suggested that project characteristics (i.e., uncertainty and complexity) might moderate the relationship between development practices and performance (Eisenhardt and Tabrizi, 1995; Fitzsimmons et al., 1991; Gerwin and Barrowman, 2002; Griffin, 1997b; Swink, 2000; Tatikonda and Rosenthal, 2000a, 2000b; Terwiesch and Loch, 1999). However, empirical evidence supporting this argument remains inconclusive.

In a sample of 72 NPD projects in the computer manufacturing industry, Eisenhardt and Tabrizi (1995) did not find any moderating effect of uncertainty on development speed. However, after splitting the sample into two segments based on high and low uncertainty they found a significant association between the use of crossfunctional teams and product development speed in an uncertain environment. This study recognized the effect of project complexity indirectly by controlling for project size.

Griffin (1997b) recognized the difference between complexity and uncertainty explicitly and examined the effect of project and process characteristics on product development cycle time in a sample of 343 projects from 11 companies. The study reported that NPD cycle times increase with increased product complexity and with product newness. However, both the interaction between use of cross-functional team and product newness and the interaction between use of formal product development process and product complexity reduce NPD cycle time. This led her to suggest that a cross-functional team "is more important in projects in which less of the design is a carryover from a previous generation" (Griffin, 1997b, p. 24). However, she did not find any direct effect of the use of a cross-functional team or a formal product development process on NPD cycle time. Neither did she find any interaction between use of cross-functional team and product complexity and the interaction between use of formal product development process and product newness. The complexity was measured by the number of functions and the uncertainty was measured by product newness.

Swink (2000) reported that the overlap and interaction of activities reduce development time and goal failure under high technological innovation but not under low technological innovation. On the contrary, Terwiesch and Loch (1999) reported that process concurrency (overlapping activities) has no effect on development times under high uncertainty but has a negative effect under low uncertainty. At the same time, in a study 120 projects from the assembled goods industry, Tatikonda and Rosenthal (2000b) failed to find any moderating effect of uncertainty (product and process technology novelty) on the relationship between a formal process and NPD goal failures. In a study of 45 NPD projects from 12 firms, Olson et al. (1995) observed that increased integration through organic, decentralized, and participative coordination mechanisms is positively associated with performance only for the innovative products, but negatively associated with less innovative products. Similarly, in a study of 34 product development projects from 9 firms, Olson et al. (2001) found that although team integration increases during a project, more integration is not necessarily better. Only integration between marketing and 
operations and integration between $\mathrm{R} \& \mathrm{D}$ and operations at the later stage of a project interact positively with project innovativeness. In fact, early integration between marketing and operations interacts negatively with project innovativeness.

In summary, the literature on process concurrency and team integration originated in the practitioner literature that is based on case studies and anecdotal evidence (Griffin, 1997b). Empirical studies are relatively few and often based on a small and/or convenience sample. Although NPD success is driven by a multiplicity of factors (Ledwith and O'Dwyer, 2009; Mallick and Schroeder, 2005), most of these studies have focused on development time as their sole performance criterion. As a result the effect of these best practices on the overall NPD performance cannot be ascertained from this literature. Moreover, many of these studies have operationalized these practices merely in terms of whether or not they are being used, thus ignoring the effect of the extent of their implementation (Gerwin and Barrowman, 2002). While scholars (Griffin, 1997b) have suggested that these best practices may interact with the project characteristics, the empirical evidence remains inconclusive, contradictory, and often a source of confusion (Gerwin and Barrowman, 2002). This study is an attempt to fill this gap in the literature.

\section{Theoretical Foundation and Hypotheses}

The OIPT (Galbraith, 1974; Kitchen and Spickett-Jones, 2003), a variant of the CT (Lawrence and Lorsch, 1967; Thompson, 1967; Woodward, 1958), is used as the foundation for research hypotheses in this study. Both theories have been used extensively in the NPD literature (Fitzsimmons et al., 1991; Griffin, 1997b; Krishnan and Ulrich, 2001; Langerak et al., 2008; Olson et al., 1995; Tatikonda and Rosenthal, 2000a, 2000b; Zirger and Hartley, 1996). The OIPT asserts that the information processing requirement of a task needs to be matched with the information processing capability of an organization to achieve a given level of performance. Any mismatch between information processing requirement and the information processing capability leads to reduction in performance. The information processing requirement can be matched with information processing capability either (1) by reducing information processing requirement or (2) by increasing information processing capability (Galbraith, 1973, 1974). For this study, the information processing requirements are determined by the project characteristics (i.e., uncertainty and complexity) and the level of process concurrency. The information processing capability is determined by the level of integration within the product development team used for its execution. The match or fit between these variables is conceptualized as interaction (Jaccard and Turrisi, 2003; Venkatraman, 1989). Therefore, the interaction between these variables is hypothesized to influence overall NPD performance.

The following sections explain how project characteristics, process concurrency, and team integration interact to define information processing requirements and information processing capability and, hence, affect the overall NPD performance.

\section{Impact of Project Characteristics on NPD Performance}

Literature has identified project complexity and uncertainty as the two key characteristics that define the difficulty level of an NPD project (Fitzsimmons et al., 1991; Griffin, 1997b; Olson et al., 1995; Sheremata, 2000; Tatikonda and Montoya-Weiss, 2001; Tatikonda and Rosenthal, 2000a, 2000b). A product development project consists of many subtasks or activities. Complexity of a product development project is determined by the number of activities involved in a project and their interdependencies (Simon, 1962). However, for most NPD projects, these activities and their interrelationships are not very clear and well understood at the beginning of a project and are often characterized as the "fuzzy front end" (Khurana and Rosenthal, 1997). As reduction of these ambiguities and uncertainties takes place throughout the product development process, activities and their interrelationships become clearer and established. Therefore, uncertainty of a product development project is determined by the level of ambiguity in the activities and their interrelationship at the beginning of the project. According to the OIPT, the greater the uncertainty and complexity, the greater the amount of information that must be processed among decision makers during project execution in order to achieve a given level of performance (Galbraith, 1973, 1974). Therefore, development teams encounter greater difficulty and take more time when developing products with a higher degree of newness (Olson et al., 1995). Uncertain and risky development tasks increase the need for coordination that leads to higher costs (Sheremata, 2000). New products require more effort, time, and resources compared with making enhancements to existing products (De Brentani, 2001). Higher level of product newness increases the development time and costs because of greater uncertainty and complexity (Griffin, 2002). 
Both a higher level of complexity and uncertainty increase the difficulty of a design task. However, the way they influence the information processing requirement is quite different. Project complexity has a direct effect on the volume of information to be processed. That is, the higher the number of tasks and their interrelationships in a development project, the higher the volume of information that needs to be processed for their execution. However, when tasks and their interrelationships are well defined and known at the outset, the type of information that needs to be processed is deterministic in nature. On the other hand, when not much is known about the tasks and/or their relationships, such is the case for a development project with high uncertainty, execution requires processing of information that is stochastic in nature. Although the level of complexity and uncertainty in a product development project affects information processing needs differently, they both increase the information processing requirement and the difficulty level of a project (Hauptman and Hirji, 1996; Tatikonda and Rosenthal, 2000a, 2000b). Therefore, a higher level of uncertainty and/or complexity is expected to have a negative effect on the project outcome. The following two hypotheses summarize these arguments:

Hla: Project uncertainty has a direct negative impact on NPD performance.

H1b: Project complexity has a direct negative impact on NPD performance.

\section{Impact of Process Concurrency on NPD Performance}

The product development process is the sequence of activities through which information is processed and research and development resources are utilized during product development. It is the mechanism through which product development resources, such as people and technologies, are deployed and managed for the execution of a product development project. While the number and the variety of the activities involved in a development process are specific to a project, in the NPD literature these activities are often classified into four general categories: (1) concept design; (2) technical design; (3) detail design; and (4) manufacturing process design (Dixon and Duffy, 1990). Traditionally, these four activities are carried out in a sequence. In a sequential process, information is processed through decomposing a development project into smaller subtasks. Integration of the subtasks is achieved through goals, specifications, and policies. Exceptions are handled through occasional team meetings. Therefore, a sequential process places less demand on the information processing requirement (Galbraith, 1974). However, proponents of concurrent product development process argue that such a process is time consuming and significant development time reduction can be achieved through overlapping these activities or execution of these activities in parallel (Clausing, 1994). On the other hand, a concurrent development process requires simultaneous consideration of many design decisions from diverse perspectives (Takeuchi and Nonaka, 1986), leading to a higher level of information processing requirements such as frequent team meetings or informal interactions (Bhattacharya, Krishnan, and Mahajan, 1998). Therefore, the degree of overlap is an important management lever for controlling the information processing requirement in an NPD project (Joglekar, Yassine, Eppinger, and Whitney, 2001; Terwiesch and Loch, 1999). Thus, an infinite number of possibilities with different levels of overlap between the activities exist for selecting a development process. For example, in a stage-gate-process (Cooper, 1990), the information processing requirement is managed through cross-functional implementation of phases between a series of gate reviews.

Because an increased level of overlap increases the information processing requirement of a product development process, the benefit of the process concurrency must be weighed against the cost of the increased information processing requirement. This is because a higher level of process concurrency is expected to produce a negative impact on overall NPD performance if the information processing requirement of the project is already very high (i.e., projects with high level of uncertainty and/or complexity) because of the added information processing requirements caused by the overlapping activities. However, it will be relatively easier to realize the benefits of high process concurrency if the information processing requirements of the project is lower (i.e., projects with low level of uncertainty and/or complexity). Similarly, a lower level of process concurrency is expected to produce a positive impact on overall NPD performance if the information processing requirement of the project is already very high (i.e., projects with high level of uncertainty and/or complexity). These arguments are summarized with the following two hypotheses:

H2a: The interaction between process concurrency and project uncertainty has a negative effect on overall NPD performance.

H2b: The interaction between process concurrency and project complexity has a negative effect on overall NPD performance. 


\section{Impact of Team Integration on NPD Performance}

Firms are typically organized into distinct departments by functional expertise, such as marketing, R\&D, and manufacturing, for efficient utilization of organizational resources through division of work. Therefore, the integration of these functions is essential for the execution of product development projects. Product development teams are created to achieve this integration of expertise across functions. However, a product development team can be structured in many different ways with different types of integration mechanisms leading to different levels of information processing capability and utilization of organizational resources, e.g., (1) a functional team; (2) a product-focused team; and (3) a matrix team (Fitzsimmons et al., 1991; Galbraith, 1973; Hayes, Wheelwright, and Clark, 1989; Mallick, 2000; Olson et al., 1995).

At the one end, a functional product development team consists of members residing in their functional department, e.g., marketing, R\&D, or manufacturing, and the projects are executed within each department independently and thrown over the wall to the next department for further execution. As the departments are organized by functional expertise, information across functions must travel vertically through the organizational hierarchy, slowing down its processing. However, such a structure facilitates accumulation of a deeper level of expertise within the departments and leads to efficient utilization of resources within each specialty. On the other end, in a product-focused team, team members with required functional expertise are structured in self-contained or dedicated teams. As each product design team has all the expertise it needs to execute a design project, the need for coordination is eliminated and the ability to process information in real time is increased. However, dedicated resource in a product-focused organization leads to inefficient utilization of $R \& D$ resources and higher costs (Galbraith, 1973).

Thus, we observe that there is a trade-off between the information processing capability and utilization of R\&D resources that is a major driver of product development cost. There are several coordination mechanisms reported in the organizational design literature such as direct contact, liaison roles, task forces, teams, integrating roles, linking managerial roles, and matrix design that can be used to balance this trade-off. A matrix organization can be viewed as a functional organization with a lateral coordination mechanism through a project manager (Galbraith, 1973). In the NPD literature, depending on the power and the authority of the project manager, the matrix organization has often been characterized as heavy-weight or light-weight project teams (Hayes et al., 1989).

Because the different integration mechanisms create different levels of information processing capability and associated cost, higher levels of integration are not always better (Fitzsimmons et al., 1991; Mallick, 2000; Olson et al., 1995). Therefore, a higher level of integration in a product development team is expected to produce a positive impact on NPD performance when there is a need for higher level of information processing capability (i.e., to execute projects with a high level of uncertainty and/or complexity). Similarly, a lower level of integration in a product development team is expected to produce a positive impact on NPD performance when there is a need for a lower level of information processing capability (i.e., to execute projects with a low level of uncertainty and/or complexity). However, a higher level of integration is expected to lower overall NPD performance when there is no need for a high level of information processing capability (i.e., to execute projects with a low level of uncertainty and/or complexity) because inefficient utilization of R\&D resources will drive up development costs. Similarly, a lower level of integration is also expected to lower overall NPD performance when there is a need for a high level of information processing capability (i.e., to execute projects with a high level of uncertainty and/or complexity). These arguments are summarized with the following two hypotheses:

H3a: The interaction between team integration and project uncertainty has a positive effect on overall NPD performance.

H3b: The interaction between team integration and project complexity has a positive effect on overall NPD performance.

Figure 1 combines all six hypotheses in a contingency model. A contingency model involves three types of variables: contextual (or contingency) variables representing situational characteristics, response variables representing managerial actions, and performance variables representing specific aspects of effectiveness that are appropriate to evaluate the fit between contextual variables and response variables. The interaction between the context variables and response variables is hypothesized to affect the performance variable (Sousa and Voss, 2008). In this study, the two project characteristics (i.e., project uncertainty and project complexity) are the context variables, the two development practices (i.e., concurrent product development and an integrated 


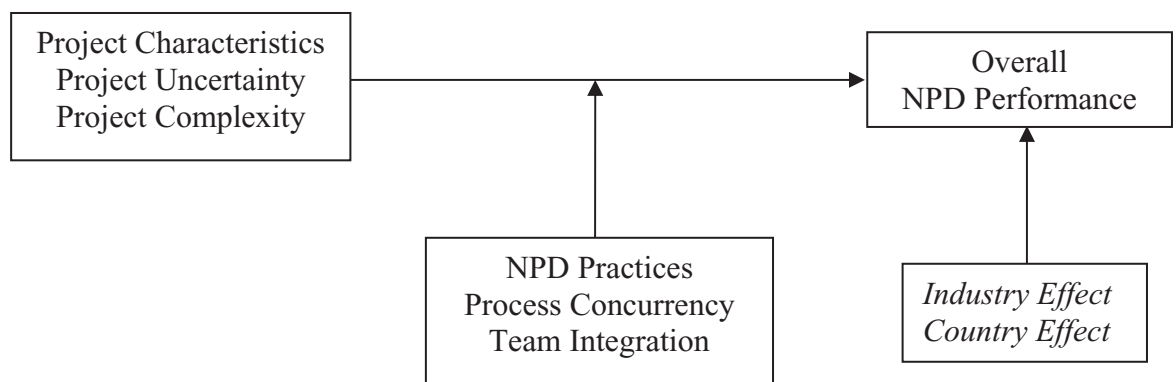

Figure 1. Hypothesized Model

product development team) are the response variables, and the overall NPD project performance is the performance variable. Accordingly, the interaction between the project characteristics and development practices is hypothesized to affect the overall NPD performance.

\section{Research Design}

Following is a description of the exploratory factor analysis (EFA) and the hierarchical linear regression methods that are being used in this study to test the hypotheses.

\section{Data Collection and Sample}

This study uses primary data from a database developed for the High Performance Manufacturing (HPM) project from three industries (i.e., electronics, automotive, and machinery) across nine countries (i.e., Austria, Finland, Germany, Italy, Japan, Korea, Spain, Sweden, and the United States). The HPM project is a large-scale comprehensive study of global manufacturing operations conducted periodically by a team of international researchers (see Schroeder and Flynn, 2001, for further details on the HPM project).

Over a two-year period, multi-item scales were developed for over 50 constructs and 200 objectives by the HPM research team involving one or more researchers from each of the nine countries. Through an iterative process, 13 questionnaires were developed with 964 items. The NPD questionnaire, in the packet of 13 questionnaires, was specifically developed for understanding the product development process during the third round of the HPM survey. The questionnaire items were developed after an extensive review of the literature by a team of experienced NPD researchers and pretested with academics and industry experts. The key respondent for the NPD questionnaire was a product development manager. The questionnaires for non-English-speaking countries were translated into the local language and translated back into English to ensure accuracy. Any discrepancies that would have compromised the content validity of the constructs were identified during this process and were resolved before administering the surveys in nonEnglish-speaking countries.

Initial telephone contact was made to randomly selected plant managers (one plant per company) to request participation. Because of the extensive internal effort involved in the data collection, each plant was requested to appoint a survey coordinator to serve as the liaison with the research team. In many cases the plant manager volunteered to serve as the survey coordinator. The survey coordinator distributed the questionnaires to the appropriate respondents, collected the completed questionnaires in sealed envelopes, and mailed the responses back to the research team.

Approximately $65 \%$ of plant managers initially contacted agreed to administer the survey. Data from 266 plants were returned. Each plant received a report containing a detailed analysis of the summary statistics for their plant and a benchmark profile of their specific industry. Plants with missing responses were eliminated, and the resulting dataset comprised 190 plants for the current study. The distribution of the plants within the sample for the current study is presented in Table 1 . Subsequent test of the sample did not reveal any nonrespondent bias in the sample (Mishra and Shah, 2009). The median sales revenue is $\$ 284$ million, the average number of employees is 659 , and the average number of product models is 120 per plant. The unit of analysis is a product development project.

\section{Measurement}

The Appendix lists the original survey question items (Q1-Q23) used for the construction of measures for testing the hypotheses presented in this study. Respondents were asked to answer all questions in relation to a specific NPD project in which the respondent participated 
Table 1. Distribution of Plants across Countries and Industries

\begin{tabular}{lcccr}
\hline & \multicolumn{4}{c}{ Industry } \\
\cline { 2 - 4 } Country & Machinery & Electronics & Transportation & Total \\
\hline Finland & 5 & 9 & 8 & 22 \\
United States & 3 & 5 & 6 & 14 \\
Japan & 8 & 7 & 10 & 25 \\
Germany & 11 & 7 & 17 & 35 \\
Sweden & 5 & 2 & 4 & 11 \\
South Korea & 7 & 6 & 8 & 21 \\
Italy & 7 & 10 & 7 & 24 \\
Austria & 6 & 9 & 2 & 17 \\
Spain & 7 & 9 & 5 & 21 \\
Total & 59 & 64 & 67 & 190 \\
\hline
\end{tabular}

within the last 5 years to eliminate inconsistencies in the unit of analysis (Flynn, Sakakibara, Schroeder, and Flynn, 1990).

The project uncertainty (UNCERT) scale is developed by taking the arithmetic average of 5 items (Q1-Q5) related to project newness (i.e., product newness, market newness, technology newness, and process technology newness) from the existing literature (Booz Allen Hamilton, Inc., 1968). Each of the 5 items is measured on a 3 -point scale ( $1=$ known to company, $2=$ new to the company, $3=$ new to the world). Principal component analysis yielded only one factor with an eigenvalue greater than one, suggesting that these 5 items represented a single unidimensional construct with all items having loadings greater than the recommended minimum of .4 (Carmines and Zeller, 1979).

Similarly, the project complexity (COMPLEX) scale is developed by taking an arithmetic average of the 3 items (Q6, Q8, and Q11) from the 6 items in the Appendix. Each of the 6 items is measured on a 7-point Likert scale with 1 as the lowest and 7 as the highest score. Principal component analysis produces two factors with eigenvalues greater than one, suggesting these 6 items represented two underlying constructs. We dropped 3 items (Q7, Q9, and Q10) that loaded on the second factor based on theoretical considerations (Jacobs, 2007; Simon, 1962) and checked the remaining 3 items to ensure that they all loaded onto a single factor with factor loadings greater than the recommended minimum of 4 (Carmines and Zeller, 1979).

The process concurrency (NPDP) and team integration (NPDO) are measured by two 4-point ordinal scales (Q12 and Q13). For NPDP, a value of one indicates that four stages of the development process are sequential and a value of four, on the other hand, indicates that the four
Table 2. Convergent and Discriminant Validity and Reliability

\begin{tabular}{lccc}
\hline & \multicolumn{3}{c}{ Factor Loadings } \\
\cline { 2 - 4 } & 1 & 2 & 3 \\
\hline Items & PERF & UNCERT & COMPLEX \\
Q15: market share & .750 & .092 & -.168 \\
Q16: technical specification & .652 & .142 & .191 \\
Q18: return on investment & .735 & -.003 & .108 \\
Q19: time to market & .676 & -.067 & .140 \\
Q22: R\&D budget & .601 & -.035 & .095 \\
Q23: overall commercial success & .787 & .136 & .018 \\
Q1: platform newness & .108 & .721 & .021 \\
Q2: product newness & .032 & .673 & .121 \\
Q3: market newness & .125 & .664 & .279 \\
Q4: product technology newness & -.074 & .605 & -.073 \\
Q5: process technology newness & .030 & .579 & .279 \\
Q6: number of tasks & .046 & .169 & .820 \\
Q8: task interdependencies & .128 & .053 & .686 \\
Q11: relative complexity & .082 & .154 & .702 \\
Reliability (Cronbach's $\alpha$ ) & .79 & .68 & .64 \\
Variance explained (cumulative \%) & 21.6 & 37.47 & 51.16 \\
\hline
\end{tabular}

stages were carried out simultaneously. Similarly, for NPDO, a value of one through four represents functional, functional matrix, project matrix, and pure project form of organization, respectively.

The project performance (PERF) scale is developed by taking an arithmetic average of 6 items (Q15, Q16, Q18, Q19, Q22, and Q23) used for measuring the success of the product development project relative to its goals (Mallick and Schroeder, 2005). These are market share, technical performance relative to specifications, return on investment, time to market, $\mathrm{R} \& \mathrm{D}$ budget, and overall commercial success. Principal component analysis yielded only one factor with an eigenvalue greater than one, suggesting that these 6 items represented a single unidimensional construct with all items having loading greater than the recommended minimum of .4 (Carmines and Zeller, 1979).

Three multi-item constructs were also tested for discriminant validity using EFA, and reliability using Cronbach's coefficient alpha (Nunnally and Bernstein, 1994). As shown in Table 2, all three constructs above have factor loadings greater than the minimum recommended .4 and none of them cross-loaded on more than one factor (Hair, Anderson, Tatham, and Black, 1998). The reliability of overall NPD performance (PERF) is higher than the recommended minimum of .7 (Carmines and Zeller, 1979). The reliability estimates for the two new constructs measuring uncertainty (UNCERT) and complexity (COMPLEX) are above the minimum acceptable 
Table 3. Descriptive Statistics and Pearson Correlations

\begin{tabular}{lcccccc}
\hline Variables & Mean & SD & PERF & UNCERT & COMPLEX & NPDP \\
\hline PERF & 4.62 & .83 & & & & \\
UNCERT & 1.51 & .44 & $.14 * *$ & & & \\
COMPLEX & 5.45 & .95 & $.19 * * *$ & $.34 * * *$ & & \\
NPDP & 2.49 & .71 & -.02 & -.07 & $.13 *$ & \\
NPDO & 2.33 & .90 & $.13 *$ & $.31 * * *$ & $.24 * * *$ & -.03 \\
\hline
\end{tabular}

*** $p \leq 0.01 ; * * p \leq 0.05 ; * p \leq 0.10$.

value of .6 for new constructs (Flynn et al., 1990) or in exploratory research (Boyer and Pagell, 2000). Therefore, we have confidence in using these measures for further analysis.

\section{Results and Discussion}

The purpose of this research project is to test empirically whether the hypothesized relationships exist between project characteristics (i.e., project uncertainty and project complexity) and NPD practices (i.e., process concurrency and team integration) and how they affect the dependent variable overall NPD performance. The following is a discussion on the empirical analysis and results corresponding to the testing of hypotheses.

\section{Analysis}

Table 3 presents the descriptive statistics and Pearson correlations between all variables used for this study. All variables have mean values close to the center of their scale except project complexity (i.e., mean $=5.45$ ). Also, data represent significant variability with respect to all five measures used in the study. Correlations between UNCERT and PERF, COMPLEX and PERF, NPDP and COMPLEX, NPDO and PERF, NPDO and UNCERT, NPDO and COMPLEX, and UNCERT and COMPLEX are all statistically significant and positive. While some of these correlations are contrary to what is being hypothesized in this study, correlations alone are not adequate to test the direct and indirect effects hypothesized in this study.

Hierarchical linear regression analysis is used to test the hypothesis. Hierarchical linear regression analysis has been used to test the performance relationships in the literature (Clark and Fujimoto, 1991; Cooper and Kleinschmidt, 1994; Griffin, 1997b). This study follows the same approach for estimating the proposed model in Figure 1. Because the data span multiple industries and multiple countries, two sets of indicator (dummy) vari- ables are used to control for any confounding effects due to differences in industry and/or country as suggested in the literature (Bstieler, 2005; Luo et al., 2010). The resulting regression model is as follows:

$$
\begin{aligned}
& \text { PERF }_{i}=\beta_{0}+\beta_{1} \text { FINLAND }_{i}+\beta_{2} \text { JAPAN }_{i} \\
& +\beta_{3} \text { GERMANY }_{i}+\beta_{4} \text { SWEDEN }_{i} \\
& +\beta_{5} \text { KOREA }_{i}+\beta_{6} \text { ITALY }_{i}+\beta_{7} \text { AUSTRIA }_{i} \\
& +\beta_{8} \text { SPAIN }_{i}+\beta_{9} \text { ELECTRONICS }_{i} \\
& +\beta_{10} \text { MACHINERY }_{i}+\beta_{11} \text { UNCERT }_{i} \\
& +\beta_{12} \text { COMPLEX }_{i}+\beta_{13} \mathrm{NPDP}_{i}+\beta_{14} \mathrm{NPDO}_{i} \\
& +\beta_{15} \mathrm{UNCERT} * \mathrm{NPDP}_{i}+\beta_{16} \text { COMPLEX } * \\
& \mathrm{NPDP}_{i}+\beta_{17} \mathrm{UNCERT} * \mathrm{NPDO}_{i} \\
& +\beta_{18} \text { COMPLEX }^{2} \mathrm{NPDO}_{i}+\beta_{19} \mathrm{NPDP} * \\
& \mathrm{NPDO}_{i}+\varepsilon_{i}
\end{aligned}
$$

where

$\operatorname{PERF}_{i}=$ performance of project $i$.

FINLAND $_{i}$, JAPAN $_{i}$, GERMANY $_{i}$, SWEDEN $_{i}$, KOREA $_{i}$, ITALY $_{i}$, AUSTRIA $_{i}$, and $\operatorname{SPAIN}_{i}$ are eight indicator variables representing nine countries with the United States as the comparison group.

ELECTRONICS $_{i}$ and MACHINERY $i$ are two indicator variables representing three industries with TRANSPORTATION as the comparison group.

UNCERT $_{i}=$ value of the uncertainty variable for project $i$. COMPLEX $_{i}=$ value of the complexity variable for project $i$. $\mathrm{NPDP}_{i}=$ level of process concurrency for project $i$. $\mathrm{NPDO}_{i}=$ level of team integration for project $i$.

Variables were entered in four stages into the hierarchical regression model (i.e., Model 1, 2, 3, and 4 in Table 4). All indicator variables (i.e., $\operatorname{FINLAND}_{i}$, JAPAN $_{i}$, GERMANY $_{i}$, SWEDEN $_{i}$, KOREA $_{i}$, ITALY $_{i}$, AUSTRIA $_{i}$, SPAIN $_{i}$, ELECTRONICS $_{i}$, and MACHINERY $_{i}$ ) for controlling any industry- and/or countryspecific effects were entered in Model 1. Model 1 is statistically significant. However, all industry- and/or country-specific effects account for only less than $5 \%$ of variation in overall NPD performance.

The two project characteristic variables (i.e., UNCERT and COMPLEX) were entered as a block in Model 2. We observe that Model 2 is statistically significant, and the incremental F-statistic test indicates that this model is an improvement over Model 1. The two project characteristics account for approximately $7 \%$ of variations in performance. The regression coefficient for UNCERT is not statistically significant, but the regression coefficient for COMPLEX is statistically significant. 
Table 4. Hierarchical Regression Model Estimation Results

\begin{tabular}{|c|c|c|c|c|}
\hline \multirow[b]{2}{*}{ Dependent variable } & \multicolumn{4}{|c|}{ PERF } \\
\hline & Model 1 & Model 2 & Model 3 & Model 4 \\
\hline Intercept & $4.912 * * *$ & $3.475 * * *$ & $3.513 * * *$ & $3.278 * * *$ \\
\hline \multicolumn{5}{|l|}{ Independent variables } \\
\hline Finland & $-.455^{*}$ & -.324 & -.360 & -.346 \\
\hline Japan & -.047 & .047 & .008 & -.075 \\
\hline Germany & -.308 & -.311 & -.294 & -.274 \\
\hline Sweden & $-.607 *$ & $-.577^{*}$ & $-.607 *$ & $-.545^{*}$ \\
\hline Korea & .165 & .250 & .257 & .257 \\
\hline Italy & -.243 & -.151 & -.171 & -.203 \\
\hline Austria & $-.644 * *$ & $-.740 * * *$ & $-.720 * * *$ & $-.727 * * *$ \\
\hline Spain & -.139 & -.131 & -.132 & -.129 \\
\hline Electronics & -.148 & -.223 & -.223 & $-.244^{*}$ \\
\hline Machinery & -.012 & .002 & -.008 & -.063 \\
\hline UNCERT & & .179 & .145 & .133 \\
\hline COMPLEX & & $.210 * * *$ & $.199 * * *$ & $.233 * * *$ \\
\hline NPDP & & & -.023 & -.017 \\
\hline NPDO & & & .062 & .090 \\
\hline UNCERT*NPDP & & & & $-.112 * *$ \\
\hline COMPLEX*NPDP & & & & -.004 \\
\hline UNCERT*NPDO & & & & -.032 \\
\hline COMPLEX*NPDO & & & & $.148 * *$ \\
\hline$N$ & 190 & 190 & 190 & 190 \\
\hline$F$ & $1.829 * *$ & $2.953 * * *$ & $2.574 * * *$ & $2.539 * * *$ \\
\hline$R^{2}$ & .093 & .167 & .171 & .211 \\
\hline Adjusted $R^{2}$ & .042 & .110 & .104 & .128 \\
\hline$\Delta R^{2}$ & .007 & .074 & .004 & .040 \\
\hline$\Delta F$ & & $7.871 * * *$ & .418 & $2.172 *$ \\
\hline
\end{tabular}

However, contrary to the relationship hypothesized in this study, it is positive. Therefore, $\mathrm{H} 1$ and $\mathrm{H} 2$ are not supported.

The two development practice variables (i.e., NPDP and NPDO) were entered as a block in the third stage in Model 3. Although Model 3 is statistically significant, the incremental F-statistic test indicates no statistically significant improvement over Model 2. Also, the regression coefficients of NPDP and NPDO are not statistically significant.

The four interaction variables (i.e., UNCERT*NPDP, COMPLEX*NPDP, UNCERT*NPDO, and COMPLEX* NPDO) were entered as a block in Model 4. Model 4 is statistically significant, and the incremental F-statistic test indicates that this model is an improvement over previous models. The four interaction variables account for approximately $4 \%$ of variation in performance. Also, the regression coefficient for UNCERT*NPDP is statistically significant and negative, and the regression coefficient for COMPLEX*NPDO is statistically significant and positive. However, regression coefficients for UNCERT*NPDO and COMPLEX*NPDP are not statistically significant. Therefore, $\mathrm{H} 2 \mathrm{a}$ and $\mathrm{H} 3 \mathrm{~b}$ are supported, but $\mathrm{H} 2 \mathrm{~b}$ and $\mathrm{H} 3 \mathrm{a}$ are not supported.

\section{Discussion}

In this section, the practical significance, possible explanations, and managerial implications of the findings of this study are discussed, and how they relate to the existing body of knowledge are identified.

First, this study (Model 2) did not find any evidence of the direct negative relationships between uncertainty (UNCERT) or product complexity (COMPLEX) and overall NPD performance (PERF) as hypothesized (i.e., $\mathrm{H} 1 \mathrm{a}$ and $\mathrm{H} 1 \mathrm{~b}$ ). On the contrary, the study found a statistically significant positive relationship between product complexity and overall NPD performance. Although the literature presents a strong theoretical argument for $\mathrm{H} 1 \mathrm{a}$ and $\mathrm{H} 1 \mathrm{~b}$, it has failed to provide any conclusive empirical evidence supporting these arguments (Clark and Fujimoto, 1991; Langerak et al., 2008; Tatikonda and Rosenthal, 2000a, 2000b; Zirger and Hartley, 1996). The failure of a growing body of empirical studies to uncover this relationship raises questions about this prevailing view. In fact, several scholars have pointed out that uncertainty and/or complexity do not necessarily cause a negative impact on overall NPD performance. Uncertainty and/or complexity are sometime a competitive necessity and can be a source of competitive advantage (Fitzsimmons et al., 1991; Hagel, 1988; Langerak et al., 2008; Mallick, 2000). This study strengthens this argument.

The managerial implication of this study is that the prevailing management bias against innovative NPD projects with a higher level of uncertainty and/or complexity is not well founded. Although managers are often tempted to undertake derivative and/or simple product development projects, this study points out that products with a higher level of uncertainty and/or complexity do not necessarily have a performance penalty. Therefore, managers should resist the temptation to fall back on me-too products or simple products. Instead, the focus should be on product excellence. Managers should be encouraged to undertake breakthrough products even if such projects increase the level of uncertainty and/or complexity. They should not assume that a difficult project will necessarily lead to poor performance. The competitive advantage is gained often by doing difficult tasks better than the competition.

Next, this study (Model 3) did not find any positive impact of the process concurrency and team integration 


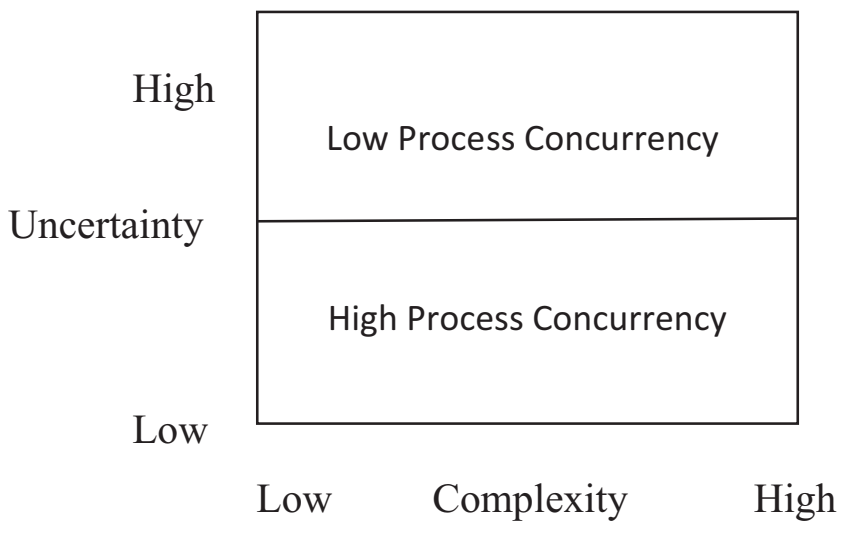

Figure 2. Results I

on overall NPD performance as proposed by the literature that promotes these two "best practices" (Clark and Fujimoto, 1991; Clausing, 1994; Hauptman and Hirji, 1996; Imai et al., 1985; Zirger and Hartley, 1996). One possible explanation is the presence of the trade-offs among various success measures of NPD projects (Mallick and Schroeder, 2005). Therefore, unlike the literature that primarily focuses on a single dimension of NPD performance, i.e., project schedule, cycle time, or cycle time goal (Gerwin and Barrowman, 2002), the use of a comprehensive NPD performance measure in this study shows no net impact of these two "best practices" on overall NPD performance on the average. Although the absence of any statistically significant relationship between process concurrency and/or team integration and overall NPD performance in Model 3 is not evidence for a proposition of its absence, it strengthens the arguments for a contingency model as proposed in this study and in the literature (Fitzsimmons et al., 1991; Griffin, 1997b; Mallick, 2000; Meyer and Utterback, 1995; Olson et al., 1995, 2001; Tatikonda and Rosenthal, 2000a, 2000b).

Finally, this study (Model 4) found a statistically significant (1) negative impact of the interaction between project uncertainty and process concurrency and (2) a positive impact of the interaction between project complexity and team integration on overall NPD performance as hypothesized (H2a and H3b). However, the study did not find any evidence of a performance impact of the interaction (1) between project complexity and process concurrency or (2) between project uncertainty and team integration as hypothesized ( $\mathrm{H} 2 \mathrm{~b}$ and $\mathrm{H} 3 \mathrm{a})$. The negative interaction between project uncertainty and process concurrency indicates that a high level of project uncertainty and a high level of process concurrency will have a negative impact on overall NPD performance (Figure 2). Therefore, a higher level of process concurrency is expected to produce better NPD performance with a

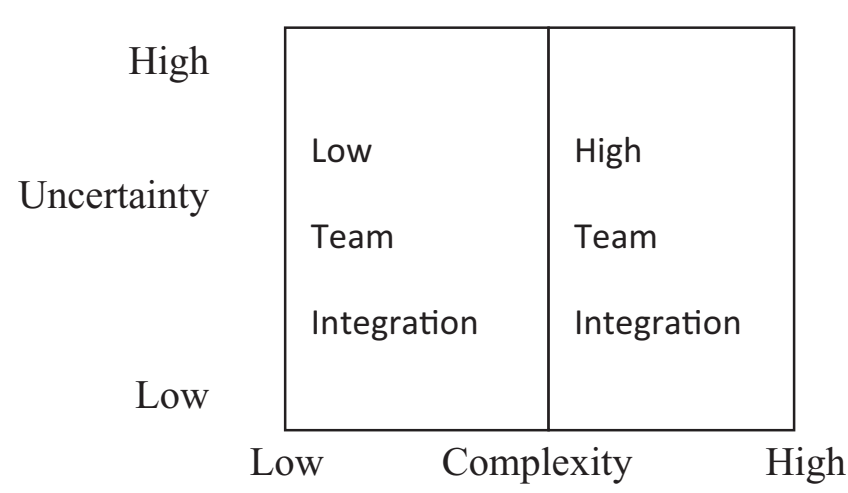

Figure 3. Results II

lower level of project uncertainty (e.g., a derivative product) and a lower level of process concurrency is expected to produce better NPD performance with a higher level of project uncertainty (e.g., innovative product). Similarly, the positive interaction between project complexity and team integration indicates that a high level of project complexity (e.g., a complex product) and a high level of team integration will have a positive impact on overall NPD performance (Figure 3). Alternatively, a low level of project complexity (e.g., a simple product) and a low level of team integration have a positive impact on overall NPD performance (see Figure 3). These findings complement the results reported in the prior literature (Griffin, 1997b; Olson et al., 1995) and strengthen the arguments that the presence of project uncertainty and/or complexity makes process concurrency less attractive (Loch and Terwiesch, 1998).

The managerial implications of these results is that managers should not be single minded about increasing process concurrency or team integration. Although these ideas appear to be very appealing, there are penalties (hidden costs) involved in these types of choices. The two results from this study (Figures 2 and 3) can be combined to provide normative guidelines for the four possible scenarios (e.g., derivative and simple product, innovative and simple product, derivative and complex product, and innovative and complex product) that will be useful to managers. As shown in Figure 4, a high level of process concurrency and a highly integrated product development team should only be used for complex derivative products. For highly innovative complex products, the use of a low level of process concurrency and a highly integrated product development team is expected to produce better performance. Simple derivative product development projects can be executed with a high level of process concurrency and development teams with low integration. However, for a simple but highly innovative product 


\begin{tabular}{c|l|l|}
\cline { 2 - 3 } High & $\begin{array}{l}\text { Low Process } \\
\text { Concurrency } \\
\text { \& Low Team }\end{array}$ & $\begin{array}{l}\text { Low Process } \\
\text { Concurrency } \\
\text { \& High Team } \\
\text { Integration }\end{array}$ \\
\hline \multirow{2}{*}{ Low } & $\begin{array}{l}\text { High Process } \\
\text { Concurrency } \\
\text { \& Low Team } \\
\text { Integration }\end{array}$ & $\begin{array}{l}\text { High Process } \\
\text { Concurrency } \\
\text { \& High Team } \\
\text { Integration }\end{array}$ \\
\cline { 2 - 3 } \\
Low Complexity
\end{tabular}

Figure 4. Managerial Implications

development project, a low level of process concurrency and a loosely integrated development team are expected to do better. Hence, there is no one-size-fits-all solution to managing NPD projects. Therefore, this study joins the expanding body of the literature that cautions against the universal application of these two best practices (Fitzsimmons et al., 1991; Griffin, 1997b; Mallick, 2000; Meyer and Utterback, 1995; Olson et al., 1995, 2001).

\section{Conclusion}

Use of a concurrent product development process and integrated product development teams have been two of the most dominant NPD paradigms for the past two decades. Yet their impact on the NPD performance is not well understood. Existing literature is mostly conceptual and case based. The few studies that have explored these two practices empirically are incomplete as they primarily focus only on product development speed. However, speed is only one of the several determinants of NPD success. As a result, the literature has remained inconclusive, with contradictory findings (Gerwin and Barrowman, 2002). This study is intended to address this gap in the literature. The study makes several contributions to the NPD literature and practice. First, these two best practices have emerged from the practitioner literature with no theoretical foundation. This study presented a conceptual framework based on information processing theory to better understand their interaction with project characteristics and impact on overall NPD performance.

Next, this study empirically tested the direct and interaction effect of project characteristics and development practices on NPD performance. Unlike previous studies that only focused on a single dimension of NPD performance (e.g., time), this study used a multidimensional performance measure, thus providing a better under- standing of the effect of these practices. This study found no evidence of a negative impact of project uncertainty and complexity on overall NPD performance as suggested in the literature. On the contrary, the study found a statistically significant positive relationship between project complexity and overall NPD performance. Moreover, unlike what is being touted in the literature, the study did not find any relationship between process concurrency or team integration with overall NPD performance. Instead, the study presents evidence that interaction between project uncertainty and process concurrency has a statistically significant negative impact on overall NPD performance and the interaction between project complexity and team integration has a statistically significant positive impact on overall NPD performance. The theoretical and practical implications of these results were presented in the previous section.

Finally, the past studies are mostly based on small and/convenience samples. This study uses a sample from three industries (i.e., transportation, machinery, and electrical equipment) across nine countries (i.e., Austria, Finland, Germany, Italy, Japan, Korea, Spain, Sweden, and the United States). The use of a multi-industry, multicountry database enhances the generalizability of the results presented in this study.

However, the study suffers from several limitations that we must point out. First, the low reliability of the two measures used for uncertainty and complexity could affect the findings of this study. Although the reliabilities of these two measures are above the acceptable cutoff value (.6) for exploratory research and/or new constructs (Boyer and Pagell, 2000; Flynn et al., 1990), a systematic approach to address this problem should be a top priority in future NPD research.

Next, another limitation of the study results from the way overall NPD performance is measured. The scale items in this study are all anchored to the project goals. Although this is a serious problem in most NPD research that uses performance measures as a goal as it is possible to adjust the goals to reflect the difficulty levels of the project which can create measurement problems, this is a widely used research practice in the NPD literature (Mallick and Schroeder, 2005). However, future research should look not only into the performance goals but also into competitiveness measures.

Finally, the results imply that there is a three-way interaction between project characteristics, process concurrency, and team integration. However, this study did not explicitly examine the effect of this three-way interaction on overall NPD performance. This would be the direction of our future research. 


\section{References}

Ancona, D. G., and D. F. Caldwell. 1992. Demography and design: Predictors of new product team performance. Organizational Science 3 (3): $321-41$.

Barczak, G., A. Griffin, and K. B. Kahn. 2009. PERSPECTIVE: Trends and drivers of success in NPD practices: Results of the 2003 PDMA Best Practices Study. Journal of Product Innovation Management 26 (1): 3-23.

Bhattacharya, S., V. Krishnan, and V. Mahajan. 1998. Managing new product definition in highly dynamic environments. Management Science 44 (11): S50-64.

Blackburn, J. D. 1991. New product development: The new time wars. In Time-based competition: The next battleground in American manufacturing, ed. J. D. Blackburn, 121-63. Homewood, IL: Business One Irwin.

Booz, Allen, Hamilton, Inc. 1968. Management of new products. Chicago: Booz, Allen, Hamilton.

Boyer, K. K., and M. Pagell. 2000. Measurement issues in empirical research: Improving measures of operations strategy and advanced manufacturing technology. Journal of Operations Management 18 (3): $361-74$.

Bstieler, L. 2005. The moderating effect of environmental uncertainty on new product development and time efficiency. Journal of Product Innovation Management 22 (3): 267-84.

Carmines, E. G., and R. A. Zeller. 1979. Reliability and validity assessment. Thousands Oak, CA: Sage Publications, Inc.

Clark, K. B. 1989. Project scope and project performance: The effect of parts strategy and supplier involvement on product development. Management Science 35 (10): 1247-63.

Clark, K. B., and T. Fujimoto. 1991. Product development performance: Strategy, organization and management in the world auto industry. Boston: Harvard Business School Press.

Clausing, D. 1994. Total quality deployment: A step-by-step guide to worldclass concurrent engineering. New York: ASME Press.

Cooper, R. G. 1990. Stage-gate system: A new tool for managing new products. Business Horizons (May/June): 44-54.

Cooper, R. G., and E. J. Kleinschmidt. 1994. Determinants of timeliness in product development. Journal of Product Innovation Management 11 (5): 381-96.

Crawford, C. M. 1992. The hidden costs of accelerated product development. Journal of Product Innovation Management 9 (3): 188-99.

De Brentani, U. 2001. Innovative versus incremental new business services: Different keys for achieving success. Journal of Product Innovation Management 18 (3): 169-84.

Dixon, J. R., and M. R. Duffy. 1990. The neglect of engineering design. California Management Review 32 (2): 9-23.

Eisenhardt, K., and B. N. Tabrizi. 1995. Accelerating adaptive processes: Product innovation in the global computer industry. Administrative Science Quarterly 40 (1): 84-110.

Ettlie, J. E. 1995. Product-process development integration in manufacturing. Management Science 41 (7): 1224-37.

Fitzsimmons, J. A., P. Kouvelis, and D. N. Mallick. 1991. Design strategy and its interface with manufacturing and marketing: A conceptual framework. Journal of Operations Management 10 (3): 398-415.

Flynn, B. B., S. Sakakibara, R. G. Schroeder, and E. J. Flynn. 1990. Empirical research methods in operations management. Journal of Operations Management 9 (2): 250-73.

Galbraith, J. R. 1973. Designing complex organizations. Reading, MA: Addison Wesley.

Galbraith, J. R. 1974. Organization design: An information processing view. Interfaces 4 (3): 28-36.

Gerwin, D., and N. J. Barrowman. 2002. An evaluation of research on integrated product development. Management Science 48 (7): 938-53.
Gerwin, D., and G. Susman. 1996. Special issue on concurrent engineering. IEEE Transactions on Engineering Management 43 (2): 118-23.

Griffin, A. 1997a. PDMA research on new product development practices: Updating trend, bench marking best practices. Journal of Product Innovation Management 14 (6): 429-558.

Griffin, A. 1997b. The effect of project and process characteristics on product development cycle time. Journal of Marketing Research 34 (1): 24-35.

Griffin, A. 2002. Product development cycle time for business-to-business products. Industrial Marketing Management 31 (4): 291-304.

Hagel, J. III 1988. Managing complexity. The McKinsey Quarterly 1988 (2): $1-23$

Hair, J. F., R. E. Anderson, R. L. Tatham, and W. C. Black. 1998. Multivariate data analysis. Upper Saddle River, NJ: Prentice-Hall.

Hauptman, O., and K. K. Hirji. 1996. The influence of process concurrency on project outcomes in product development: An empirical study of cross-functional teams. IEEE Transactions on Engineering Management 43 (2): 153-64.

Hayes, R. H., S. C. Wheelwright, and K. B. Clark. 1989. Dynamic manufacturing: Creating the learning organization. New York: The Free Press.

Imai, K., I. Nonaka, and H. Takeuchi. 1985. Managing the new product development process: How the Japanese companies learn and unlearn. In The uneasy alliance, ed. K. B. Clark, R. H. Hayes, and C. Lorenz, 337-81. Boston: Harvard Business School Press.

Jaccard, J., and R. Turrisi. 2003. Interaction effects in multiple regression (2nd ed.). Thousand Oaks, CA: Sage Publications.

Jacobs, M. 2007. Product complexity: A definition and impacts on operations. Decision Line 38 (5): 6-12.

Joglekar, N. R., A. A. Yassine, S. D. Eppinger, and D. E. Whitney. 2001. Performance of coupled product development activities with a deadline. Management Science 47 (12): 1605-20.

Khurana, A., and S. R. Rosenthal. 1997. Integrating the fuzzy front end of new product development. Sloan Management Review 38 (2): 103-21.

Kitchen, P. J., and G. Spickett-Jones. 2003. Information processing: A critical literature review and future research directions. International Journal of Market Research 45 (1): 73-98.

Krishnan, V., and K. T. Ulrich. 2001. Product development decisions: A review of the literature. Management Science 47 (1): 1-21.

Langerak, F., and E. J. Hultink. 2005. The impact of new product development acceleration approaches on speed and profitability: Lessons for pioneers and fast followers. IEEE Transactions on Engineering Management 52 (1): 30-42.

Langerak, F., E. J. Hultink, and A. Griffin. 2008. Exploring mediating and moderating influences on the links among cycle time, proficiency in entry timing, and new product profitability. Journal of Product Innovation Management 25 (4): 370-85.

Larson, E. W., and D. H. Gobeli. 1989. Significance of project management structure on development success. IEEE Transactions on Engineering Management 36 (2): 119-25.

Lawrence, P. R., and J. W. Lorsch. 1967. Organization and environment: Managing differentiation and integration. Boston: Harvard Business School Press.

Ledwith, A., and M. O’Dwyer. 2009. Market orientation, NPD performance, and organizational performance in small firms. Journal of Product Innovation Management 26 (6): 651-61.

Loch, C. H., and C. Terwiesch. 1998. Communication and uncertainty in concurrent engineering. Management Science 44 (8): 1032-48.

Luo, C., D. N. Mallick, and R. G. Schroeder. 2010. Collaborative product development: Exploring the role of internal coordination capability in supplier involvement. European Journal of Innovation Management 13 (2): 244-66

MacCormack, A., R. Verganti, and M. Iansiti. 2001. Developing products on Internet time: The anatomy of a flexible development process. Management Science 47 (1): 133-50. 
Mallick, D. N. 2000. The design strategy framework. Design Management Journal 11 (3): 66-73.

Mallick, D. N., and R. G. Schroeder. 2005. An integrated framework for measuring product development performance in high technology industries. Production and Operations Management 14 (2): 142-58.

McDonough, E. F. III. 1993. Faster new product development: Investigating the effects of technology and characteristics of the project leader and team. Journal of Product Innovation Management 10 (3): 241-50.

McDonough, E. F. III. 2000. Investigation of factors contributing to the success of cross-functional teams. Journal of Product Innovation Management 17 (3): 221-35.

McDonough, E. F. III, and G. Barczak. 1992. The effects of cognitive problem-solving orientation and technology familiarity on faster new product development. Journal of Product Innovation Management 9 (1): 44-52.

Meyer, M. H., and J. M. Utterback. 1995. Product development cycle time and commercial success. IEEE Transactions on Engineering Management 42 (4): 297-304.

Mishra, A. A., and R. Shah. 2009. In union lies strength: Collaborative competence in new product development and its performance effects. Journal of Operations Management 27 (4): 324-38.

Moffat, L. K. 1998. Tools and teams: Competing models of integrated product development project performance. Journal of Engineering and Technology Management 15 (1): 55-85.

Nunnally, J. C., and I. H. Bernstein. 1994. Psychometric theory (3rd ed). New York: McGraw-Hill.

Olson, E. M., O. C. Walker Jr., and R. W. Ruekert. 1995. Organizing for effective new product development: The moderating role of product innovativeness. Journal of Marketing 59 (1): 48-62.

Olson, E. M., O. C. Walker Jr., R. W. Ruekert, and J. M. Bonnerd. 2001. Patterns of cooperation during new product development among marketing, operations and R\&D: Implication for project performance. Journal of Product Innovation Management 18 (4): 258-71.

Parry, M. E., M. Song, P. C. De Weerd-Nederhof, and K. Visscher. 2009 The impact of NPD strategy, product strategy, and NPD processes on perceived cycle time. Journal of Product Innovation Management 26 (6): 627-37.

Rosenthal, S. R. 1992. Effective product design and development: How to cut lead time and increase customer satisfaction. Homewood, IL: Business One Irwin.

Rusinko, C. A. 1999. Exploring the use of design-manufacturing integration (DMI) to facilitate product development: A test of some practices. IEEE Transactions on Engineering Management 46 (1): 56-71.
Schroeder, R. G., and B. B. Flynn. 2001. High performance manufacturing: Global perspective. New York: Wiley.

Scott, S. G. 1997. Social identification effects in product and process development teams. Journal of Engineering and Technology Management 14 (2): 97-127.

Sheremata, W. A. 2000. Centrifugal and centripetal forces in radical new product development under time pressure. Academy of Management Review 25 (2): 389-408.

Simon, H. A. 1962. The architecture of complexity. Proceedings of the American Philosophical Society 106 (6): 467-82.

Sousa, R., and C. A. Voss. 2008. Contingency research in operations management practices. Journal of Operations Management 26 (6): 697-713.

Swink, M. 2000. Technological innovativeness as a moderator of new product design integration and top management support. Journal of Product Innovation Management 17 (3): 208-20.

Takeuchi, H., and I. Nonaka. 1986. The new product development game. Harvard Business Review 64 (1): 137-46.

Tatikonda, M. V., and M. M. Montoya-Weiss. 2001. Integrating operations and marketing perspectives of product innovation: The influence of organizational factors and capabilities on development performance. Management Science 47 (1): 151-72.

Tatikonda, M. V., and S. R. Rosenthal. 2000a. Technology novelty, project complexity, and product development project execution success: A deeper look at task uncertainty in product innovation. IEEE Transactions on Engineering Management 47 (1): 74-87.

Tatikonda, M. V., and S. R. Rosenthal. 2000b. Successful execution of development projects: Balancing firmness and flexibility in the innovation process. Journal of Operations Management 18 (4): 401-25.

Terwiesch, C., and C. H. Loch. 1999. Measuring the effectiveness of overlapping development activities. Management Science 45 (4): 455-65.

Thompson, J. D. 1967. Organizations in action. New York: McGraw-Hill.

Venkatraman, N. 1989. The concept of fit in strategy research: Toward verbal and statistical correspondence. Academy of Management 14 (3): $423-44$

Wheelwright, S. C., and K. B. Clark. 1992. Revolutionizing product development: Quantum leaps in speed, efficiency, and quality. New York: The Free Press.

Woodward, J. 1958. Management and technology. London: HMSO.

Zirger, B. J., and J. L. Hartley. 1996. The effect of acceleration techniques on product development time. IEEE Transactions on Engineering Management 43 (2): 143-52. 


\section{Appendix: Part of original question items used in this study}

Please answer the following questions in the context of a recently completed product development project, for which you were part of the team.

Q1. This product was:

1 A derivative product based on modifications to existing products

2 A platform product for starting a new product line

3 A breakthrough product with new technology

Q2. This product was:

1 Similar to our existing products

2 Different from what we have manufactured, but similar to products offered by our competitors

3 Different from what we have manufactured, and no similar products were offered by our competitors

Q3. The market for the product was:

1 An existing market that we served.

2 An existing market, but new to this company

3 The market did not exist prior to development of this product

Q4. The product technology for this product was:

1 Available within the company

2 New to the company, but available from outside

3 New to the world

Q5. The process technology used to produce this product was:

1 Similar to technology we had used before

2 Required major changes in existing manufacturing

3 Completely new

\begin{tabular}{|c|c|c|c|c|c|c|c|}
\hline $\begin{array}{l}\text { Strongly } \\
\text { Disagree }\end{array}$ & Disagree & $\begin{array}{l}\text { Slightly } \\
\text { Disagree }\end{array}$ & Neutral & $\begin{array}{l}\text { Slightly } \\
\text { Agree }\end{array}$ & Agree & $\begin{array}{l}\text { Strongly } \\
\text { Agree }\end{array}$ & $\begin{array}{l}\text { Please indicate the extent to which you agree or } \\
\text { disagree with the following statements about this } \\
\text { project, your plant and organization. }\end{array}$ \\
\hline 1 & 2 & 3 & 4 & 5 & 6 & 7 & Q6. This project included many tasks. \\
\hline 1 & 2 & 3 & 4 & 5 & 6 & 7 & $\begin{array}{l}\text { Q7. It was difficult to define tasks in the beginning } \\
\text { of the project. }\end{array}$ \\
\hline 1 & 2 & 3 & 4 & 5 & 6 & 7 & $\begin{array}{l}\text { Q8. The tasks in this project were highly } \\
\text { interdependent }\end{array}$ \\
\hline 1 & 2 & 3 & 4 & 5 & 6 & 7 & $\begin{array}{l}\text { Q9. It was easy to define the interdependence } \\
\text { among tasks in this project. }\end{array}$ \\
\hline 1 & 2 & 3 & 4 & 5 & 6 & 7 & $\begin{array}{l}\text { Q10. There were many departments involved with } \\
\text { this project }\end{array}$ \\
\hline 1 & 2 & 3 & 4 & 5 & 6 & 7 & Q11. Overall, this was a relatively simple project \\
\hline
\end{tabular}

Q12. Check the form of organization that most closely describes the way this project was organized.

1 Functional: The project was assigned to a functional division of the organization.

2 Functional matrix: Team members were assigned to this project, as well as others. The project manager's role was limited to coordinating the efforts of the functional groups involved.

3 Project matrix: Team members were assigned to this project, as well as others. The project manager had direct authority to make decisions about personnel and work flow activities.

4 Pure project: The project was organized as a self-contained unit with its own technical staff and its own administration. The project manager had full line authority over the project, with all members of the project team directly responsible to the project manager.

Q13: The product development process can be described by the following four stages:

1. Concept development/idea generation

2. Product planning/technical and market feasibility

3. Detailed design development and prototypes

4. Manufacturing process development/pilot production

Check the statement below that most closely describes your product development process:

1 The four stages were sequential.

2 The four stages were sequential with some overlap.

3 The four stages had significant overlap.

4 The four stages were carried out simultaneously. 
Please rate the success of this product development project, relative to its goals.

\begin{tabular}{|c|c|c|c|c|c|c|c|c|c|c|c|c|c|c|c|}
\hline 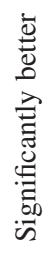 & $\begin{array}{c}\bar{D} \\
\stackrel{D}{D} \\
D\end{array}$ & 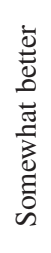 & 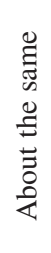 & 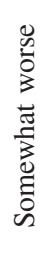 & $\begin{array}{l}0 \\
0 \\
\vdots \\
\vdots \\
\vdots\end{array}$ & 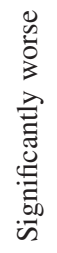 & & 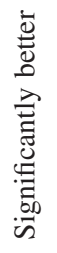 & 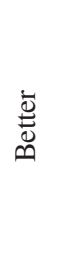 & 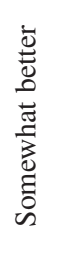 & 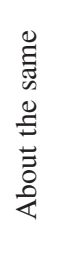 & 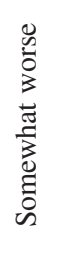 & 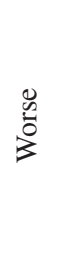 & 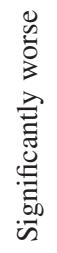 & \\
\hline 7 & 6 & 5 & 4 & 3 & 2 & 1 & Q14. Customer satisfaction & 7 & 6 & 5 & 4 & 3 & 2 & 1 & Q19. Time to market \\
\hline 7 & 6 & 5 & 4 & 3 & 2 & 1 & Q15. Market share & 7 & 6 & 5 & 4 & 3 & 2 & 1 & Q20. Ease of manufacturing \\
\hline 7 & 6 & 5 & 4 & 3 & 2 & 1 & $\begin{array}{l}\text { Q16. Technical performance } \\
\text { relative to specifications }\end{array}$ & 7 & 6 & 5 & 4 & 3 & 2 & 1 & Q21. Unit manufacturing cost \\
\hline 7 & 6 & 5 & 4 & 3 & 2 & 1 & Q17. Overall profitability & 7 & 6 & 5 & 4 & 3 & 2 & 1 & Q22. R\&D budget \\
\hline 7 & 6 & 5 & 4 & 3 & 2 & 1 & Q18. Return on investment & 7 & 6 & 5 & 4 & 3 & 2 & 1 & Q23. Overall commercial success \\
\hline
\end{tabular}

